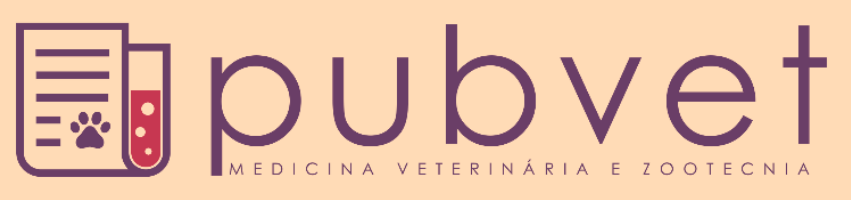

https://doi.org/10.31533/pubvet.v15n08a900.1-12

\title{
Criptorquidismo em equinos: Revisão de literatura e relato de 20 casos
}

\author{
Ubiratan Pereira de Melo $^{1^{*} \bullet}$ (D) Cíntia Ferreira ${ }^{1} \bullet$ \\ ${ }^{1}$ Docentes do Curso de Medicina Veterinária da Uninassau/Natal. Natal/RN, Brasil. \\ *Autor para correspondência, E-mail: ubiratan_melo@yahoo.com.br
}

\begin{abstract}
Resumo. Este artigo tem por objetivo revisar os aspectos anatômicos e fisiopatológicos do criptorquidismo na espécie equina, bem como relatar uma série de 20 casos tratados clínica ou cirurgicamente. O criptorquidismo consiste em uma alteração complexa do desenvolvimento, limitada ao sexo, sendo o mais prevalente defeito de desenvolvimento não letal do equino. Este distúrbio ocorre quando há falha na descida normal de um ou ambos os testículos, a partir da sua posição fetal na área sub-lombar, através do canal inguinal, para a bolsa escrotal. Entre os anos de 2013 e 2020, vinte equinos, idade média de 7,1 $\pm 1,69$ anos, foram examinados para diagnóstico e tratamento de criptorquidismo. Todos os animais foram examinados na propriedade de origem e submetidos a exame clínico geral. Exame clínico geral (anamnese e exame físico), palpação trans retal e ultrasonografia (trans retal e trans abdominal) foram realizadas em todos os animais para identificação da gônada retida. À exceção de dois casos, todos os animais foram encaminhados à cirurgia pelo critério do histórico do criptorquidismo relatado pelo proprietário e identificação da gônada retida no momento do exame clínico. A remoção do testículo criptorquídico foi realizada por meio da laparotomia pelo flanco. A técnica escolhida se mostrou de fácil aplicabilidade à nível de campo, e nenhuma complicação foi observada nesta série de casos.
\end{abstract}

Palavras-chave: Equino, gubernáculo, bolsa escrotal, testículo, laparotomia

\section{Cryptorchidism in horses: literature review and report of 20 cases}

\begin{abstract}
Abstrat. This article aims to review the anatomical and pathophysiological aspects of cryptorchidism in the equine, as well as to report a series of 20 cases treated clinically or surgically. Cryptorchidism consists of a complex developmental change, limited to sex, being the most prevalent non-lethal developmental defect in the horse. This disorder occurs when there is a failure in the normal descent of one or both testicles, from their fetal position in the sub-lumbar area through the inguinal canal to the scrotum. Between the years 2013 and 2020, twenty horses, with an average age of $7.1+1.69$ years, were examined for the diagnosis and treatment of cryptorchidism. All animals were examined on the property of origin and underwent a general clinical examination. General clinical examination (anamnesis and physical examination), transrectal palpation and ultrasonography (transrectal and trans abdominal) were performed on all animals to identify the retained gonad. With the exception of two cases, all animals were referred for surgery according to the criteria of the history of cryptorchidism reported by the owner and identification of the gonad retained at the time of the clinical examination. The cryptorchid testicle was removed by flank laparotomy. The chosen technique proved to be easily applicable at the field level, and no complications were observed in this series of cases.
\end{abstract}

Keywords: Equine, gubernacle, scrotum, testis, laparotomy 


\title{
Criptorquidia en caballos: revisión de la literatura e informe de 20 casos
}

\begin{abstract}
Resumen. Este artículo tiene como objetivo revisar los aspectos anatómicos y fisiopatológicos de la criptorquidia en la especie equina, así como reportar una serie de 20 casos tratados clínica o quirúrgicamente. La criptorquidia consiste en un cambio de desarrollo complejo, limitado al sexo, siendo el defecto de desarrollo no letal más prevalente en el caballo. Este trastorno ocurre cuando hay una falla en el descenso normal de uno o ambos testículos, desde su posición fetal en la zona sublumbar, a través del canal inguinal, hasta el escroto. Entre los años 2013 y 2020, veinte caballos, con una edad promedio de 7,1 + 1,69 años, fueron examinados para el diagnóstico y tratamiento de la criptorquidia. Todos los animales se examinaron en la propiedad de origen y se sometieron a un examen clínico general. Se realizó un examen clínico general (anamnesis y examen físico), palpación transrectal y ecografía (transrectal y trans abdominal) en todos los animales para identificar la gónada retenida. Con la excepción de dos casos, todos los animales fueron remitidos para cirugía de acuerdo con los criterios de historia de criptorquidia reportada por el propietario y la identificación de la gónada retenida en el momento del examen clínico. El testículo de la criptorquidia se extrajo mediante laparotomía de flanco. La técnica elegida demostró ser de fácil aplicación a nivel de campo y no se observaron complicaciones en esta serie de casos.
\end{abstract}

Palabras clave: Equino, gubernáculo, escroto, testículo, laparotomía

\section{Introdução}

A descida testicular até a bolsa escrotal é um clássico exemplo de dimorfismo sexual que ainda não pode ser totalmente explicado. Não é um processo simples, mas parece ter vários estágios, com várias interações anatômicas e influências hormonais. Durante a evolução dos mamíferos, a gônada masculina assumiu uma posição progressivamente mais baixa em relação a sua contra parte feminina, eventualmente assumindo uma localização extra-abdominal dentro de uma bolsa escrotal na maioria dos mamíferos modernos (Hutson et al., 1997).

Desde os tempos da primeira guerra mundial, quando o equino era primordial para as atividades militares e do campo, o criptorquidismo tem se constituído em tema amplamente discutido na medicina interna equina, pela frequente dificuldade de se realizar um diagnóstico preciso e, também, pela relativa complexidade do ato cirúrgico para remoção do testículo retido (Alves et al., 2002).

Apesar da disponibilidade atual de recursos diagnósticos complementares de alta precisão, a exemplo de dosagens hormonais, ultrassonografia e videolaparoscopia, muitos desses recursos são onerosos e inacessíveis aos proprietários de baixa renda e por isso não vastamente utilizados, principalmente nas regiões mais carentes do país. Independente dos avanços obtidos nas últimas décadas em relação aos medicamentos, técnicas cirúrgicas e anestésicas, material e equipamentos, a maior parte das castrações de equinos ainda é realizada por leigos ("práticos"), bem como ainda são poucos os veterinários que se habilitam a realizar a criptorquidectomia, principalmente à campo (Alves et al., 2002).

O criptorquidismo representa a falha, uni ou bilateral, que ocorre durante a descida dos testículos para a bolsa escrotal, constituindo no tipo mais comum de diferenciação anômala do sistema genital masculino sendo frequente em carnívoros, caprinos, equinos e, ocasionalmente, bovinos (Ribeiro et al., 2014). Até recentemente, a percepção geral era que a criptorquidia se constituía numa doença única com herdabilidade moderada, penetrância incompleta, expressa apenas em machos, e concentrada por endogamia ou minimizada pela seleção negativa dos machos afetados (Amann \& Veeramachaneni, 2018).

A literatura descreve certo grau de predisposição racial para a afecção em equinos da raça Quarto de Milha, Percheron, Mangalarga Marchador e animais sem raça definida. Denominado comumente de roncolho, o equino criptorquídico frequentemente apresenta comportamento semelhante ao garanhão, mas alguns indivíduos podem apresentar traços de agressividade (Alves et al., 2002; Cattelan et al., 2004).

Este artigo tem por objetivo revisar os aspectos anatômicos e fisiopatológicos do criptorquidismo na espécie equina, bem como relatar uma série de 20 casos tratados clínica ou cirurgicamente. 


\section{Criptorquidismo}

O criptorquidismo consiste em uma alteração complexa do desenvolvimento, limitada ao sexo, sendo o mais prevalente defeito de desenvolvimento não letal do equino (Schumacher et al., 2013). O termo criptorquidia é uma combinação de três palavras gregas, "kriptós" (oculto), "orchis" (testículo) e "idion" (pequeno), sendo assim, criptorquidia significa a ausência de um ou ambos os testículos na sua localização anatômica normal, a bolsa escrotal ou escroto (Schade et al., 2017).

Este distúrbio ocorre quando há falha na descida normal de um ou ambos os testículos, a partir da sua posição fetal na área sub-lombar, através do canal inguinal, para a bolsa escrotal (Schade et al., 2017). Embora ambos os testículos possam falhar em descer para a bolsa escrotal, a retenção unilateral é nove vezes mais prevalente do que a bilateral (Rodgerson \& Hanson, 1997).

A bolsa escrotal do equino é um divertículo pré-púbico de pele que contém os testículos, seus ductos associados e a porção distal dos cordões espermáticos. Encontra-se dividida na linha média pela rafe escrotal que é contínua com a rafe do prepúcio, pênis e períneo. Intimamente aderida à pele escrotal existe uma camada de tecido conectivo e músculo involuntário, a túnica dartos. Este músculo relaxa com o calor e se contrai com o frio para regular a temperatura testicular (Köning \& Liebich, 2011).

Mamoulakis et al. (2012) classificaram a posição dos testículos nos mamíferos como trans abdominal e inguino-escrotal, e cada categoria pode ser subdividida em três sub-grupos:

$\checkmark$ Trans abdominal:

- posição 1: embrionário (sem descendência da posição ancestral/embrionária)

- posição 2: intermediária (parcialmente descido, posição intra-abdominal)

- posição 3: inguinal interno

$\checkmark$ Inguino-escrotal:

- posição 4: emergente (alguma parte se projeta através do anel inguinal),

- posição 5: além do anel inguinal, mas não dentro de uma bolsa escrotal verdadeira)

- posição 6: escrotal (em uma bolsa escrotal verdadeira).

De acordo com essa classificação, os testículos normais do equino se encontram na posição 6 (Mamoulakis et al., 2012).

Vários relatos sugerem base genética para o criptorquidismo nos equinos (Blanchard et al., 1998). Alguns métodos postulados de hereditariedade citados na literatura incluem: (1) transmissão por gene autossômico recessivo simples; (2) transmissão por gene autossômico dominante e (3) transmissão de pelo menos dois fatores genéticos, sendo um dos quais, localizado nos cromossomos sexuais (Blanchard et al., 1998; Schumacher et al., 2013). No entanto, segundo Schumacher et al. (2013) e Sprayberry \& Robinson (2014) nenhum estudo tem apoiado um mecanismo genético plausível até o momento.

A ocorrência de criptorquidismo nos garanhões é de considerável importância econômica, pois os túbulos seminíferos do testículo retido são rudimentares e incapazes de produzir espermatozoides viáveis. No entanto, deve ser ressaltado que criptorquídicos unilaterais são férteis, mas têm produção reduzida de espermatozoides, enquanto aqueles afetados bilateralmente são estéreis. A exposição do testículo à alta temperatura abdominal ou do canal inguinal parece ser responsável pela hipoplasia dos túbulos seminíferos e resulta em um testículo pequeno e flácido. As células de Leydig, produtoras de andrógenos, de um testículo criptorquídico são funcionais porque não são tão sensíveis ao calor quanto as células dos túbulos seminíferos e produzem testosterona, embora em concentrações reduzidas, de modo que o equino criptorquídico exibe comportamento sexual (Bergin et al., 1970).

\section{Desenvolvimento e descida testicular}

As gônadas fetais equinas surgem retro-peritonealmente das cristas gonadais do embrião caudais ao rim por volta dos 27 dias de gestação, e se diferenciam em testículos por volta dos 40 dias de gestação

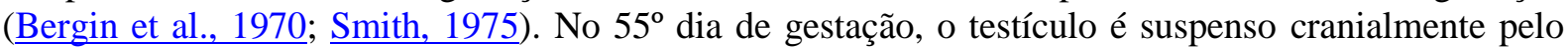
ligamento suspensório e dorsalmente pelo mesórquio (Blanchard et al., 1998; Fleury et al., 2007). Na 
sua parte caudal existe outro ligamento denominado gubernáculo que se estende no sentido ventral para a região inguinal (Figura 1) (Alves et al., 2002; Cattelan et al., 2004).

As células intersticiais começam a se multiplicar na $6^{\mathrm{a}}$ semana de gestação causando hipertrofia do testículo até que, aos 5 meses de gestação, o testículo seja quase tão grande quanto o de um garanhão adulto e entre em contato com o rim e o anel inguinal profundo. Esta fase de hipertrofia testicular corresponde a um período de alta concentração sérica de estrogênio na égua (Thompson, 2006).

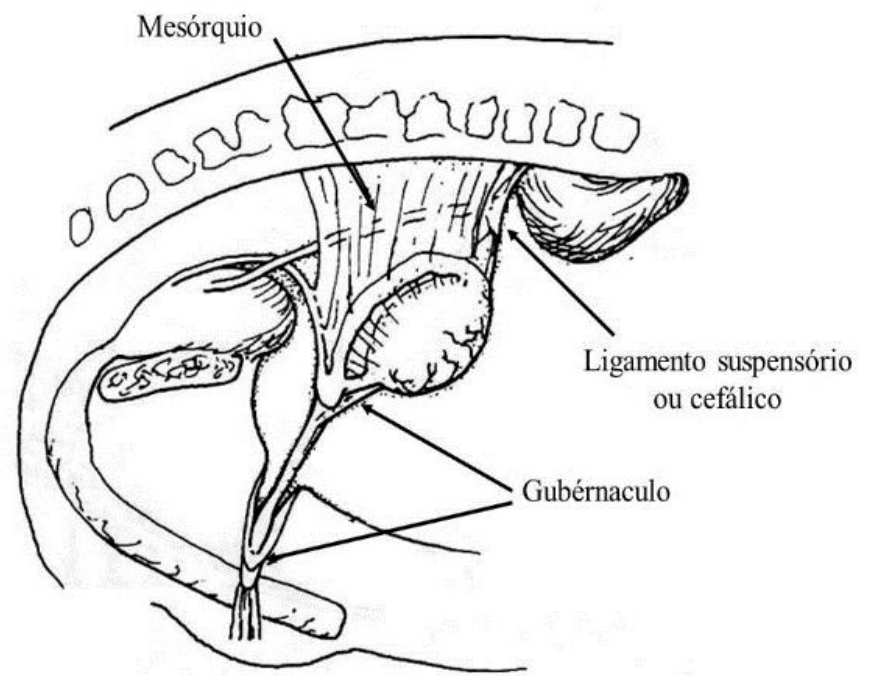

Figura 1. Fixações do testículo fetal no equino. Adaptado de Rodgerson \& Hanson (1997).

O gubernáculo testicular é um cordão mesenquimal fetal retroperitoneal que se estende entre o pólo caudal do testículo fetal e a bolsa escrotal e orienta o testículo fetal em sua descida da superfície ventral do rim até sua posição final na bolsa escrotal. O gubernáculo fetal pode ser dividido em três partes: (1) a parte cranial, que fica entre o testículo e o epidídimo; (2) a parte média, que fica entre o epidídimo e o ponto em que o gubernáculo penetra a parede abdominal no local do futuro canal inguinal e (3) a parte caudal ou escrotal, que se estende da parede abdominal no local do futuro canal inguinal até a bolsa escrotal (Köning \& Liebich, 2011).

O gubernáculo se estende da extremidade caudal do testículo até o canal inguinal e termina em uma expansão em forma de botão entre os músculos abdominais oblíquos internos e externos. No $45^{\circ}$ dia de gestação, o peritônio invade o tecido sub-peritoneal em torno dessa expansão extra-abdominal do gubernáculo para formar o processo vaginal. Por volta dos 5 meses de gestação, o ligamento suspensório atrofia e o epidídimo desce para o processo vaginal enquanto o testículo permanece no abdômen (Bergin et al., 1970).

Aos 8 1/2 meses de gestação, o gubernáculo começa a encurtar. Simultaneamente, o testículo regride de tamanho, principalmente por causa da perda de células intersticiais, até durante o último mês de gestação quando passa a ter um décimo de seu tamanho anterior (Bergin et al., 1970). Estima-se que nessa fase, o testículo alcance peso entre 5 e 10 gramas (Cox, 1999). O epidídimo e o gubernáculo subperitoneal aumentam de diâmetro, dilatando o anel vaginal e o canal inguinal. Ao mesmo tempo, uma elevação na pressão intra-abdominal permite que o testículo passe para o canal inguinal entre 270 e 300 dias de gestação. A massa do gubernáculo extra-abdominal impede que o testículo se mova diretamente para a bolsa escrotal, de modo que, ao nascimento, a maioria dos testículos se encontra no interior do canal inguinal. Esta porção extra-abdominal do gubernáculo pode ser muito grande ao nascimento e facilmente confundida com um testículo (Bergin et al., 1970; Smith, 1975).

A descida testicular completa ocorre em torno de 315 dias de gestação até o décimo dia pós-parto (Alves et al., 2002). Após a descida, o testículo volta a aumentar de tamanho, enquanto o gubernáculo diminui se diferenciando em três segmentos (Alves et al., 2002):

$\checkmark \quad$ Ligamento próprio do testículo: liga o polo caudal do testículo à cauda do epidídimo;

$\checkmark \quad$ Ligamento caudal do epidídimo: liga a cauda do epidídimo à túnica vaginal;

$\checkmark$ Ligamento escrotal: liga a túnica vaginal ao escroto. 
O ligamento escrotal de um testículo retido abdominal às vezes é referido como extensão inguinal do gubernáculo. Esses ligamentos podem ser anormalmente longos se o testículo não descer. A função inadequada do gubernáculo pode resultar na retenção abdominal ou inguinal de um testículo (Trotter \& Aanes, 1981; Valdez et al., 1979).

Nas demais espécies, os testículos parecem passar pelo canal rapidamente, pois em dissecções de fetos é raro encontrar um testículo realmente no canal inguinal. No entanto, durante a fase final gestação, um testículo distorcido em forma de salsicha pode ser encontrado no canal inguinal dos fetos, indicando que o testículo deve ser deformado para conseguir a passagem. Atualmente, acredita-se que a passagem inguinal em todas as espécies ocorre quase como resultado de movimentos fetais que aumentam a pressão intra-abdominal e, de fato, herniam o testículo através do canal inguinal (Cox, 1999).

A pressão intra-abdominal tem papel auxiliar em facilitar a saída gonadal do abdômen. Embora a pressão intra-abdominal não seja um fator durante a descida trans abdominal, assume importância no trânsito pelo canal inguinal e subsequente migração do testículo para a bolsa escrotal. A força da pressão intra-abdominal não só pode ser aplicada diretamente no testículo, mas também pode agir indiretamente criando a ponta do processo vaginal e, assim, estabilizando-o de modo que o gubernáculo possa exercer alguma tração no testículo (Hutson et al., 1997).

O testículo direito é o menor dos dois e, portanto, tende a preceder o esquerdo na bolsa escrotal. Esta diferença de tamanho persiste e pode permitir que o testículo direito retorne ao canal inguinal no início do período neonatal, sendo uma possível causa de criptorquidia inguinal (Shira \& Genetzky, 1982). No entanto, os anéis vaginais se contraem até aproximadamente $1 \mathrm{~cm}$ de diâmetro durante as primeiras semanas de vida neonatal e tornam-se tão fibrosos que o testículo não pode ser forçado em nenhuma das direções. Dessa forma, é muito pouco provável que haja descida do testículo abdominal para a posição inguinal, como também o retorno de um testículo já descido à cavidade abdominal (Alves et al., 2002; Cox, 1999). A incidência da retenção inguinal diminui com a idade, enquanto a incidência da retenção abdominal aumenta com a idade (Rodgerson \& Hanson, 1997).

Aceitando que existem três localizações gerais para os testículos não escrotais, e que essa descida testicular envolve três fases, segue-se que a criptorquidia reflete a manifestação de pelo menos três alterações pré-natais: a) falha em iniciar e completar translocação abdominal do testículo; b) falha ao iniciar e concluir a migração trans-inguinal de um testículo e c) falha em iniciar e concluir a migração inguino-escrotal de um testículo (Amann \& Veeramachaneni, 2018).

\section{Anatomia do canal inguinal e classificação do criptorquidismo}

O canal inguinal é uma passagem oblíqua na parede abdominal através da qual atravessa o cordão espermático, o nervo genitofemoral, a vascularização pudenda externa e os vasos linfáticos eferentes dos linfonodos inguinais superficiais (Ashdown, 1963; Köning \& Liebich, 2011). A abertura interna do canal inguinal, o anel inguinal profundo ou interno, é uma fenda dilatável com cerca de $16 \mathrm{~cm}$ de comprimento em um equino de tamanho médio, limitada cranialmente pela borda caudal do músculo oblíquo abdominal interno, ventro-medialmente pelo músculo reto abdominal e tendão pré-púbico, e caudalmente pelo ligamento inguinal. A abertura externa do canal inguinal, o anel inguinal superficial ou externo, é uma fenda de 10 a $12 \mathrm{~cm}$ de comprimento no músculo oblíquo abdominal externo (Köning \& Liebich, 2011).

A borda medial do anel inguinal superficial encontra-se diretamente abaixo da borda medial do anel inguinal profundo, tornando a parede medial do canal inguinal muito curta. $\mathrm{O}$ anel inguinal superficial é direcionado crânio-lateralmente, e o anel inguinal profundo é direcionado dorso-lateralmente, tornando os ângulos laterais dos anéis amplamente divergentes. O comprimento total do canal inguinal em um equino de tamanho médio é de cerca de $15 \mathrm{~cm}$ quando medido ao longo do cordão espermático, mas depende da idade e condição física. A parede do canal inguinal é revestida pelo peritônio formando a túnica vaginal (Alves et al., 2002; Budras et al., 2003; Köning \& Liebich, 2011). Após a descida testicular ocorre um espessamento do peritônio na origem da túnica vaginal, denominado anel vaginal. $\mathrm{O}$ anel vaginal possui de $1 \mathrm{a} 2 \mathrm{~cm}$ de diâmetro e acredita-se que funcione como proteção contra a ocorrência de hérnia indireta (Alves et al., 2002). 
O canal inguinal é o ponto de referência para a classificação do criptorquidismo nos equinos. Classifica-se como criptorquidia abdominal completa quando o testículo e as estruturas anexas não passam pelo anel vaginal, localizando-se na cavidade abdominal. Neste caso, o testículo se situa normalmente entre o rim e a bexiga ou próximo ao anel inguinal interno (Alves et al., 2002; Amann \& Veeramachaneni, 2018). Portanto, tanto o anel quanto o processo vaginal são subdesenvolvidos. Quando parte do epidídimo e/ou ducto deferente estiver no canal inguinal, o equino é classificado como criptorquídico abdominal incompleto ou abdomino-inguinal. Outra possibilidade de criptorquidia abdominal incompleta é caracterizada por partes do epidídimo, ducto deferente e testículo insinuadas no canal inguinal, enquanto outras partes ficam dessas estruturas ficam no abdômen (Alves et al., 2002; Amann \& Veeramachaneni, 2018). A criptorquidia inguinal ocorre quando o testículo passa pelo anel vaginal, porém não alcança a bolsa escrotal. Nestes casos, o testículo pode estar retido no canal inguinal ou em posição subcutânea, adjacente ao anel inguinal externo (Alves et al., 2002; Amann \& Veeramachaneni, 2018).

Um testículo subcutâneo geralmente é encontrado no triângulo femoral, mas ectopia do processo vaginal pode colocar o testículo a alguma distância ou perto de uma bolsa escrotal malformada. Ocasionalmente, um testículo escrotal pode mais tarde ser retraído permanentemente no canal inguinal (testículo retrátil) ou um testículo inicialmente considerado inguinal ou subcutâneo pode mais tarde ser posicionado permanentemente na bolsa escrotal (descida tardia). Essa migração é mais comum em equinos do que bovinos ou ovinos (Amann \& Veeramachaneni, 2018).

O que deu errado durante a descida testicular, em um sentido simples, pode ser deduzido a partir da identificação do testículo retido e o conhecimento do processo da descida testicular. Um testículo abdominal reflete o fracasso em iniciar e translocação abdominal completa do testículo, então o testículo não está posicionado perto do anel inguinal interno, mas sim perto da bexiga ou a meio caminho entre a área inguinal e o rim. Um testículo inguinal reflete falha para iniciar a migração trans-inguinal completa. Um testículo subcutâneo reflete falha para iniciar a migração inguino-escrotal completa da cauda epidídimo e testículo, de fora do canal inguinal ao seu destino na bolsa escrotal. Em equinos, muitos testículos retidos estão dentro do canal inguinal per se e poucos são subcutâneos, mas testículos que na verdade são subcutâneos, muitas vezes são classificados inadequadamente como inguinal (Amann \& Veeramachaneni, 2018).

A falha na descida testicular direita e esquerda ocorre com frequência quase igual. $75 \%$ dos testículos não descidos esquerdos são retidos dentro do abdômen, enquanto $40 \%$ dos testículos direitos não descidos estão localizados na região abdominal. Cerca de $10-15 \%$ dos criptorquídicos são afetados bilateralmente (Schumacher et al., 2013).

\section{Etiologia}

Segundo Alves et al. (2002) no passado acreditava-se que somente o gubernáculo era responsável pela descida testicular à bolsa escrotal, porém, sabe-se atualmente ser dependente da interação de inúmeros fatores, preponderantemente hormonais. A descida é iniciada pela ação da testosterona que induz maturação na medula espinhal e nas raízes neurais periféricas, incluindo o nervo genitofemoral que atravessa o canal inguinal (Cox, 1999). A ação neuroendócrina estimula, principalmente, três estruturas, o gubernáculo, o testículo e o ligamento suspensório resultando em modificações morfológicas de maneira sincrônica, seriada e interdependente, possibilitando a descida testicular (Alves et al., 2002).

Eventos que levam ao criptorquidismo nos equinos não foram completamente determinados, mas deficiência na produção de gonadotrofina pela glândula pituitária ou placenta resulta na produção insuficiente de andrógenos pelos testículos. Esses andrógenos são responsáveis pelo desenvolvimento do processo vaginal, vasos testiculares e ducto deferente, e por mudanças no gubernáculo, todas necessárias para a descida dos testículos até a bolsa escrotal. Em vez de agir diretamente no gubernáculo, os andrógenos provavelmente agem principalmente no corpo celular do nervo genitofemoral na medula espinhal. O nervo genitofemoral, que inerva o gubernáculo, faz com que o gubernáculo se diferencie, criando um potencial espaço no qual o testículo desce sob a influência da pressão intra-abdominal. Os andrógenos, portanto, agem no gubernáculo indiretamente e provavelmente devem fazê-lo em um momento específico durante a gestação (Hadžiselimović, 1982; Hutson et al., 1990; Hutson et al., 1997; Ng et al., 2005). 
A persistência do ligamento suspensório cranial localizado no polo caudal do rim causa retenção testicular. O testículo é suspenso dorsalmente pelo mesórquio à parede do corpo e sua face cranial é fixada à face caudal do rim pelo ligamento suspensório cranial durante grande parte da gestação. Este ligamento se forma por volta do $55^{\circ}$ dia de gestação, mas regride aos 150 dias de gestação. A falha do ligamento em regredir faz com que o testículo fique retido abdominalmente, complicando de tal forma a cirurgia para remoção do testículo (Ortved et al., 2014; Wilson \& Nixon, 1986). A complexidade do processo de descida testicular sugere que a causa da falha é multifatorial (Alves et al., 2002; Wilson \& Nixon, 1986). Aceita-se atualmente que existe uma multiplicidade das causas de criptorquidia, incluindo genética, epigenética e componentes ambientais (Amann \& Veeramachaneni, 2018).

\section{Diagnóstico}

O diagnóstico de criptorquidia (Figura 2) é baseado no histórico, palpação externa e trans retal, ultrasonografia trans retal e trans abdominal, ensaios hormonais, além da exploração cirúrgica do canal inguinal (Schumacher et al., 2013).

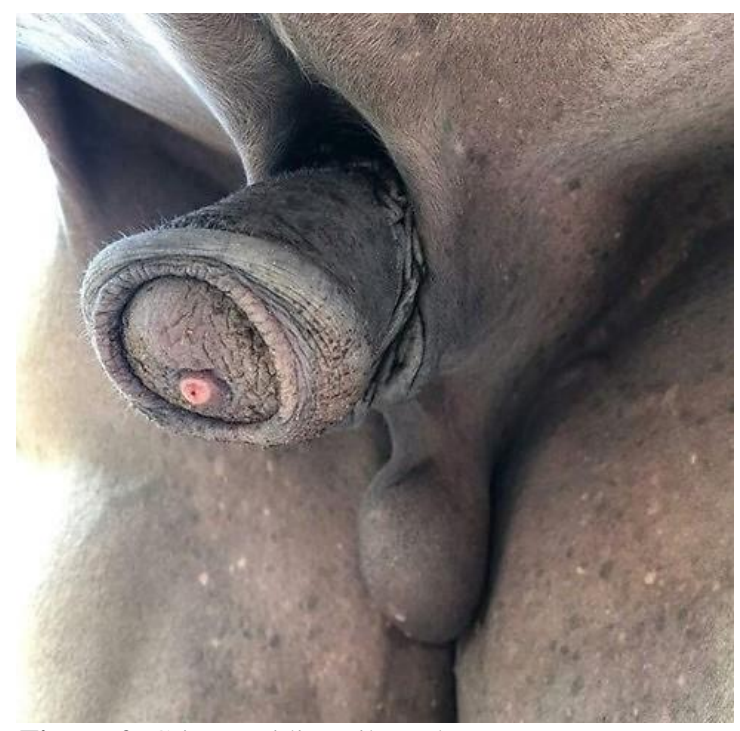

Figura 2. Criptorquidia unilateral.

Para um castrado aparente que exibe comportamento de garanhão e cuja história de castração seja desconhecida, o exame trans retal pode ser útil. Falha em palpar um testículo abdominal por reto, no entanto, não deve ser considerado diagnóstico. Um anel vaginal de um cavalo castrado é palpável como uma leve depressão, mas o anel vaginal de um garanhão é grande o suficiente para acomodar um dedo. Uma criptorquidia abdominal parcial (ou seja, aquele cujo epidídimo desceu para o canal) não pode ser distinguido pelo exame dos anéis vaginais de um cavalo cujos testículos desceram pelo anel vaginal (Alves et al., 2002).

Quando o testículo não se encontra na região inguinal, a palpação trans retal pode ser realizada, objetivando a identificação da gônada e dos anéis inguinais (Bergin et al., 1970; ; Schumacher et al., 2013). Entretanto, tal exame fornece resultados contraditórios devido a mobilidade e a consistência flácida que o testículo retido apresenta (Stickle \& Fessler, 1978).

Método auxiliar à palpação interna e externa, a ultrassonografia (inguinal, trans retal e/ou trans abdominal) permite confirmar a posição testicular e determinar o tamanho do testículo retido (Schumacher et al., 2013). A ultrassonografia inguinal combinada com a trans retal apresenta-se como um meio diagnóstico sensível, com $100 \%$ de correlação entre a localização do testículo pela utilização do ultrassom e posterior confirmação por cirurgia. Além disso, a ultrassonografia trans abdominal pode ser realizada em cavalos de qualquer tamanho sem a necessidade de contenção química, além de risco diminuído para o equino e o examinador, quando comparada a ultrassonografia trans retal, sendo facilmente realizada em situações de campo (Schade et al., 2017). 
Quando a história e o exame físico são inadequados para determinar se um cavalo possui um dos testículos retido, os testes hormonais podem ser usados para distinguir entre as causas psíquicas ou hormonais do comportamento persistente de garanhão (Schumacher et al., 2013), pois garanhões e criptorquídicos têm concentrações séricas hormonais mais elevadas do que equinos castrados (Cattelan et al., 2004). Entretanto, Shira \& Genetzky (1982) advertem que este teste sozinho não pode ser usado de forma confiável para detectar tecido testicular no animal suspeito de criptorquidia devido a variações entre os indivíduos. Os níveis de testosterona citados por estes variam de $65-1600 \mathrm{pg} / \mathrm{ml}$ em equinos com tecido testicular e 11-20 pg/ml para castrados verdadeiros. Já outros artigos, citam que equinos castrados apresentam valores médios de testosterona sérica de $0,12 \mathrm{ng} / \mathrm{mL}(0,03-0,15 \mathrm{ng} / \mathrm{mL})$, enquanto animais com tecido testicular (garanhões e criptorquídicos) possuem valores médios que variam de 0,72 a $0,98 \mathrm{ng} / \mathrm{mL}(0,38-1,2 \mathrm{ng} / \mathrm{mL})$ (McKinnon et al., 2011).

O teste de estimulação com gonadotrofina coriônica humana (hCG) é considerado um método mais preciso para determinar a presença de tecido testicular, sendo indicado quando a mensuração da concentração de testosterona sérica basal é inconclusiva (Blanchard et al., 1998). O teste consiste na comparação da concentração sérica basal de testosterona, coletada antes da administração intravenosa de 6.000 a 12.000 UI de hCG, com aquela observada após uma hora, três horas, 24 horas ou mesmo três dias após administração da gonadotrofina (McKinnon et al., 2011). A hCG estimula a síntese e secreção de testosterona pelas células de Leydig (propriedades semelhantes ao LH), levando a uma elevação na concentração de testosterona 1 a 2 horas após sua aplicação (Schade et al., 2017).

Equinos criptorquídicos apresentam aumento de três vezes a concentração sérica de testosterona após o estímulo da gonadotrofina, enquanto castrados apresentam aumento que varia de zero a duas vezes a concentração basal. No entanto, fatores como a localização do testículo, idade do animal e estação do ano influenciam a resposta ao teste. Testículos abdominais são menos responsivos ao estímulo pelo hCG que testículos escrotais, e resposta mais pronunciada é observada no verão, em comparação ao inverno, devido a variação sazonal na concentração de testosterona. Além disto, equinos com idade inferior a 18 meses e criptorquídicos abdominais bilaterais, em muitos casos, não são capazes de produzir testosterona suficiente, após o estímulo pelo hCG, para diferenciá-los de animais castrados (Schade et al., 2017).

Recentemente descobriu-se ser possível diagnosticar o criptorquidismo por urinálise ou dosagem do hormônio anti-mülleriano (Claes et al., 2014). Os esteroides servem como marcadores urinários para identificação de atividade testicular em equinos, auxiliando na identificação de criptorquídicos, os quais exibem perfil de esteroides urinários semelhantes ao demais, podendo ser facilmente identificados pelo método de cromatografia em fase gasosa e espectrometria de massa (Leung et al., 2011). O hormônio anti-mülleriano é uma glicoproteína formada a partir do testículo fetal, sendo responsável pela regressão mülleriana no feto masculino (Amann \& Veeramachaneni, 2018).

\section{Tratamento}

O tratamento hormonal para o criptorquidismo é descrito desde 1930 nos seres humanos (Schade et al., 2017) consiste na administração de hormônios ( $\mathrm{GnRH}$ - gonadotrofina coriônica humana) com o objetivo de induzir a produção de andrógenos e consequente aumento do tamanho testicular, estimulando a descida dos testículos retidos para o escroto (Cox et al., 1986; Schade et al., 2017). O tratamento clínico para estimular a descida testicular do testículo retido nos equinos é controverso, tanto em relação a sua eficácia quanto a questões éticas. Apesar de relatos sugerirem que a administração de hormônios possa auxiliar na descida testicular em alguns garanhões, a percepção geral é que o tratamento clínico não é eficiente (Alves et al., 2002; Schumacher et al., 2013).

$\mathrm{O}$ tratamento cirúrgico do criptorquidismo envolve diferentes técnicas, as quais devem ser aplicadas, levando em consideração a localização do testículo retido, preferência e experiência do cirurgião, fatores econômicos e temperamento do animal (Cattelan et al., 2004). Segundo Alves et al. (2002), Cattelan et al. (2004) e Schumacher et al. (2013) as abordagens cirúrgicas para remoção de testículos retidos incluem a criptorquidectomia inguinal, parainguinal, suprapúbica paramediana, abordagem pelo flanco e a via laparoscópica. Para cada uma destas abordagens, exceto abordagem pelo flanco e a via laparoscópica, o animal deve estar sob anestesia geral (Alves et al., 2002; Schumacher et al., 2013). 


\section{Casuística}

Entre os anos de 2013 e 2020, vinte equinos, quatro sem raça definida e 16 da raça Quarto de Milha, com idade média de 7,1 $\pm 1,69$ anos, foram examinados para diagnóstico e tratamento de criptorquidismo conforme demonstrado na tabela 1 . Todos os animais foram examinados na propriedade de origem e submetidos a exame clínico geral. Após exame clínico (anamnese e exame físico), palpação trans retal e ultrassonografia (trans retal e trans abdominal) foram realizadas em todos os animais para identificação da gônada retida.

Tabela 1. Distribuição do criptorquidismo em equinos segundo raça, idade, comportamento, histórico anterior de orquiectomia e localização do tecido retido.

\begin{tabular}{|c|c|c|c|c|c|c|}
\hline Raça & Idade, anos & Comportamento & Orquiectomia anterior & Testículo retido & Localização & Tratamento \\
\hline Sem Raça Definida & 10 & Agressivo & Sim & Direito & Abdominal & Cirúrgico \\
\hline Sem Raça Definida & 5 & Normal & Sim & Direito & Abdominal & Cirúrgico \\
\hline Sem Raça Definida & 9 & Agressivo & Sim & Direito & Abdominal & Cirúrgico \\
\hline Quarto de Milha & 9 & Agressivo & Não & Direito & Abdominal & Cirúrgico \\
\hline Quarto de Milha & 8 & Normal & Não & Esquerdo & Abdominal & Cirúrgico \\
\hline Quarto de Milha & 7 & Normal & Não & Esquerdo & Abdominal & Cirúrgico \\
\hline Quarto de Milha & 8 & Normal & Não & Direito & Abdominal & Cirúrgico \\
\hline Quarto de Milha & 7 & Normal & Não & Direito & Abdominal & Cirúrgico \\
\hline Quarto de Milha & 6 & Normal & Não & Esquerdo & Abdominal & Cirúrgico \\
\hline Quarto de Milha & 7 & Normal & Sim & Direito & Abdominal & Cirúrgico \\
\hline Quarto de Milha & 8 & Normal & Não & Esquerdo & Abdominal & Cirúrgico \\
\hline Quarto de Milha & 2 & Agressivo & Não & Direito & Inguinal externo & Clínico* \\
\hline Quarto de Milha & 3 & Normal & Não & Direito & Abdominal & Cirúrgico \\
\hline Quarto de Milha & 3 & Normal & Não & Esquerdo & Inguinal externo & Clínico* \\
\hline Quarto de Milha & 8 & Normal & Não & Direito & Abdominal & Cirúrgico \\
\hline Quarto de Milha & 9 & Agressivo & Não & Direito & Abdominal & Cirúrgico \\
\hline Quarto de Milha & 8 & Normal & Não & Esquerdo & Abdominal & Cirúrgico \\
\hline Quarto de Milha & 7 & Normal & Não & Direito & Abdominal & Cirúrgico \\
\hline Quarto de Milha & 8 & Agressivo & Não & Direito & Abdominal & Cirúrgico \\
\hline Sem Raça Definida & 10 & Agressivo & Não & Direito & Abdominal & Cirúrgico \\
\hline
\end{tabular}

*Animais receberam administração de GnRH.

À exceção de dois casos, todos os animais foram encaminhados à cirurgia pelo critério do histórico do criptorquidismo relatado pelo proprietário e identificação da gônada retida no momento do exame clínico. Os dois animais que não foram submetidos ao procedimento cirúrgico receberam administração de GnRH para promover a descida testicular, apesar das considerações éticas realizadas junto aos proprietários. Em ambos os casos, o testículo se localizava no anel inguinal externo.

No período pré-operatório, os animais foram submetidos a jejum alimentar de 24 horas e jejum hídrico de seis horas. O acesso cirúrgico foi realizado através de laparotomia pelo flanco, direito ou esquerdo, dependendo da localização do testículo ao exame físico, com o equino em estação quadrupedal.

Precedendo a laparatomia pelo flanco, os animais foram submetidos a novo exame clínico e laboratorial. Após sedação com $1,0 \mathrm{mg} / \mathrm{kg}$ peso vivo de cloridrato de xilazina, administrado por via intravenosa, foi realizada anestesia local infiltrativa em forma de "L" invertido, na pele, tecido subcutâneo e camadas musculares, com cloridrato de lidocaína a $2 \%$ com vasoconstritor. Após a preparação do campo operatório, foi realizada uma incisão vertical da pele de aproximadamente 15 centímetros de comprimento no flanco, no ponto central equidistante do rebordo costal, processos transversos das vértebras lombares e a tuberosidade coxal.

A seguir, no mesmo sentido da incisão cutânea, foi realizada a incisão do músculo oblíquo abdominal externo, e em sequência, divulsão romba dos músculos oblíquo abdominal interno e transverso abdominal e por fim, a incisão do peritônio. Ao ser localizada, era realizada a remoção da gônada criptorquídica. Após a retirada da gônada retida era realizada a laparorrafia. A síntese da parede abdominal foi realizada com uma sutura contínua em massa na musculatura abdominal, com fio categute cromado $\mathrm{n}^{\circ} 3$, sendo a sutura da pele com padrão simples separada, com fio de náilon monofilamentar 
0,40 mm agulhado e esterelizado em oxietileno. Nos cavalos criptórquios inguinais a gônada afetada foi removida por orquiectomia inguinal.

Após realização do procedimento, terapia anti-inflamatória e antibiótica sistêmica foi realizada através da administração intravenosa (IV) de $4,4 \mathrm{mg} / \mathrm{kg}$ de fenilbutazona, uma vez ao dia (SID), por sete dias e administração intramuscular (IM) de Penicilina G benzatina $25.000 \mathrm{UI} / \mathrm{kg}$ SID, por sete dias. Os cuidados no pós-operatório incluíram avaliação da presença de dor ou de complicações secundárias ao ato cirúrgico, como hemorragia e infecção.

\section{Discussão}

O diagnóstico do criptorquidismo envolve a realização de exame clínico completo (Cattelan et al., 2004) incluindo a exploração cuidadosa das áreas escrotal e inguinal visando a identificação do testículo retido ou cicatriz de intervenção cirúrgica anterior. Apesar do exame interno por palpação trans retal objetivando a identificação da gônada criptorquídica e dos anéis vaginais e/ou inguinais internos (Bergin et al., 1970) e fornecer resultados contraditórios devido à mobilidade e consistência flácida do testículo retido (Stickle \& Fessler, 1978), no presente relato o exame físico interno possibilitou a identificação da gônada em todos os casos, posteriormente confirmada via ultrassonografia.

Diversos autores afirmam que em equinos com histórico desconhecido e sem testículos palpáveis no escroto, o método diagnóstico mais confiável seria a dosagem hormonal de androgênios ou estrogênios (Cattelan et al., 2004; Cox et al., 1986; McKinnon et al., 2011), em nenhum dos animais foi realizada dosagem hormonal para confirmação do criptorquidismo, uma vez que o exame clínico e de imagem possibilitou a identificação do testículo retido. Quatro animais do presente relato já haviam sido submetidos à exame clínico e intervenção cirúrgica anteriores para resolução da criptorquidia, no entanto, conforme relatos dos proprietários permaneceram apresentando comportamento de garanhão. Esses quatro animais foram reexaminados e a gônada retida localizada intra-abdominalmente.

Corroborando com estudo de Stickle \& Fessler (1978), a raça mais acometida no presente relato foi a raça Quarto de Milha (80\%). Já num estudo realizado na região sudeste do Brasil por Cattelan et al. (2004) observou-se maior prevalência em equinos da raça Mangalarga $(28,6 \%)$, seguidos da Quarto de Milha (26,2\%), animais sem raça definida (19,1\%), Brasileiro de Hipismo (14,3\%), Piquira (4,8\%), Puro Sangue Andaluz $(4,8 \%)$ e Puro Sangue Inglês $(2,4 \%)$. Entretanto, em outro estudo nacional Marques \& Ferreira (1987) apontaram maior prevalência do criptorquidismo em equinos sem raça definida, seguida pela Mangalarga e Campolina. Diferenças relacionadas a prevalência do criptorquidismo entre o presente estudo e os supracitados são resultantes provavelmente da raça de equinos prevalente na região, seja nos criatórios ou sociedades hípicas e esportivas, onde o estudo foi realizado.

Segundo Cattelan et al. (2004), o tratamento cirúrgico do criptorquidismo envolve diferentes técnicas, que devem ser aplicadas levando em consideração a localização do testículo retido, preferência e experiência do cirurgião, fatores econômicos e temperamento do animal (Silva-Meirelles et al., 2017). das abordagens utilizadas para a realização da criptorquidectomia, apenas a inguinal e a parainguinal permitem a remoção não invasiva do testículo retido. Uma abordagem não invasiva é realizada quando o testículo é removido através da introdução de apenas um ou dois dedos do cirurgião na cavidade abdominal, sendo o testículo retirado por meio da tração sobre o gubernáculo, testículo, epidídimo, ou ductos deferentes, após a ruptura do processo vaginal (Schade et al., 2017). Apesar da laparotomia pelo flanco ser considerada uma técnica invasiva para a resolução cirúrgica no criptorquidismo abdominal, não foram observadas complicações em nenhum dos animais no presente estudo.

$\mathrm{Na}$ abordagem cirúrgica dos casos relatados, a gônada criptorquidica sempre era removida primeiro, corroborando com Blanchard et al. (1998) que afirmam que independente da técnica cirúrgica, no caso do criptorquidismo unilateral o testículo retido deve ser sempre o primeiro a ser removido, pois caso a cirurgia tenha de ser interrompida, por qualquer motivo, permanece um indicador externo de criptorquidismo, o que permite diferenciar facilmente um equino castrado de um criptorquídico.

O protocolo terapêutico pós-cirurgia foi eficaz em prevenir a ocorrência de dor e complicações sépticas. Apesar dos potenciais efeitos colaterais da fenilbutazona relatados na literatura (Melo et al., 2009), nenhum dos animais do presente relato apresentou toxicidade relacionada ao uso da fenilbutazona. 


\section{Considerações finais}

O criptorquidismo representa uma alteração na descida testicular de ocorrência relativamente frequente em equinos. A identificação precisa da localização do testículo criptorquídico permite a escolha da melhor técnica cirúrgica para realização da criptorquidectomia de modo a minimizar as possíveis complicações associadas ao procedimento.

\section{Referências}

Alves, G. E. S., Faleiros, R. R., \& Macoris, D. G. (2002). Criptorquidia em equinos. Cadernos Técnicos de Veterinária e Zootecnia, 38, 7-17.

Amann, R. P., \& Veeramachaneni, D. N. R. (2018). Cryptorchidism and associated problems in animals. Animal Reproduction, 3(2), 108-120.

Ashdown, R. R. (1963). The anatomy of the inguinal canal in the domesticated mammals. Veterinary Record, 75, 1345-1351.

Bergin, W. C., Gier, H. T., Marion, G. B., \& Coffman, J. R. (1970). A developmental concept of equine cryptorchism. Biology of Reproduction, 3(1), 82-92. https://doi.org/10.1093/biolreprod/3.1.82.

Blanchard, T. L., Varner, D. D., \& Schumacher, J. (1998). Manual of equine reproduction. Mosby.

Budras, K.-D., Sack, W. O., \& Rock, S. (2003). Anatomy of the horse: an illustrated text. Mosby.

Cattelan, J. W., Macoris, D. G., Barnabé, P. A., Urbinati, E. C., \& Malheiros, E. B. (2004). Criptorquismo em eqüinos: aspectos clínico-cirúrgicos e determinação da testosterona sérica. Arquivo Brasileiro de Medicina Veterinária e Zootecnia, 56(2), 150-156. https://doi.org/10.1590/s0102-09352004000200003.

Claes, A., Ball, B. A., Corbin, C. J., \& Conley, A. J. (2014). Anti-Müllerian hormone as a diagnostic marker for equine cryptorchidism in three cases with equivocal testosterone concentrations. Journal of Equine Veterinary Science, 34(3), 442-445. https://doi.org/10.1016/j.jevs.2013.09.001.

Cox, J. E. (1999). Disturbed testicular descent in horses-principles, diagnosis and therapy. Pferdeheilkunde, 15(6), 503-505. https://doi.org/10.21836/pem19990604.

Cox, J. E., Redhead, P. H., \& Dawson, F. E. (1986). Comparison of the measurement of plasma testosterone and plasma oestrogens for the diagnosis of cryptorchidism in the horse. Equine Veterinary Journal, 18(3), 179-182. https://doi.org/10.1111/j.2042-3306.1986.tb03589.x.

Fleury, P. D. C., Alonso, M. A., Sousa, F. A. C., Andrade, A. F. C., \& Arruda, R. P. (2007). Uso da gonadotrofina coriônica humana (hCG) visando melhorar as características reprodutivas e fertilidade de receptoras de embriões eqüinos. Revista Brasileira de Reprodução Animal, 31, $27-31$.

Hadžiselimović, F. (1982). Pathogenesis and treatment of undescended testes. European Journal of Pediatrics, 139(4), 255-265.

Hutson, J M, Williams, M. P., Fallat, M. E., \& Attah, A. (1990). Testicular descent: new insights into its hormonal control. Oxford Reviews of Reproductive Biology, 12, 1-56.

Hutson, John M, Hasthorpe, S., \& Heyns, C. F. (1997). Anatomical and functional aspects of testicular descent and cryptorchidism. Endocrine Reviews, 18(2), 259-280. https://doi.org/10.1210/er.18.2.259.

Köning, H. E., \& Liebich, H. G. (2011). Anatomia dos animais domésticos texto e atlas colorido. Editora Artmed.

Leung, D. K. K., Tang, F. P. W., Wan, T. S. M., \& Wong, J. K. Y. (2011). Identification of cryptorchidism in horses by analysing urine samples with gas chromatography/mass spectrometry. The Veterinary Journal, 187(1), 60-64. https://doi.org/10.1016/j.tvj1.2009.10.010

Mamoulakis, C., Skolarikos, A., Schulze, M., Scoffone, C. M., Rassweiler, J. J., Alivizatos, G., Scarpa, R. M., \& de la Rosette, J. J. (2012). Results from an international multicentre double-blind randomized controlled trial on the perioperative efficacy and safety of bipolar vs monopolar transurethral resection of the prostate. International-British Journal of Urology, 109(2), 240.

Marques, J. A., \& Ferreira, H. I. (1987). Orquiectomia nos eqüinos criptorquídicos em posição quadrupedal. ARS Veterinaria, 3, 219-221. 
McKinnon, A. O., Squires, E. L., Vaala, W. E., \& Varner, D. D. (2011). Equine reproduction. John Wiley \& Sons.

Melo, U. P., Fiório, R. C., Araújo, T. B. S., \& Ferreira, C. (2009). Intoxicação por fenilbutazona em equino: relato de caso. Acta Veterinaria Brasilica, 3(2), 111-116. https://doi.org/10.21708/avb.2009.3.2.1265.

Ng, S. L., Bidarkar, S. S., Sourial, M., Farmer, P. J., Donath, S., \& Hutson, J. M. (2005). Gubernacular cell division in different rodent models of cryptorchidism supports indirect androgenic action via the genitofemoral nerve. Journal of Pediatric Surgery, 40(2), 434-441. https://doi.org/10.1016/j.jpedsurg.2004.10.010.

Ortved, K. F., Stewart, A. W., Fubini, S. L., \& Hackett, R. P. (2014). Surgical treatment of 4 horses for cryptorchidism caused by failure of regression of the cranial suspensory ligament of the testis. Veterinary Surgery, 43(3), 266-270. https://doi.org/10.1111/j.1532-950X.2014.12156.x.

Ribeiro, M. G., Ribeiro, L. V. P., Silva, J. R., \& Meirelles, G. P. (2014). Estudo retrospectivo de casos cirúrgicos de criptorquidismo equino no noroeste do Paraná. Revista Brasileira de Ciência Veterinária, 21, 160-162. https://doi.org/10.4322/rbcv.2014.377.

Rodgerson, D. H., \& Hanson, R. R. (1997). Cryptorchidism in horses. I. Anatomy, causes, and diagnosis. The Compendium on Continuing Education for the Practicing Veterinarian, 19, 1280-1288.

Schade, J., Gonçalves, G. R., Massiel, J. L., Fernando, A., \& Souza, L. C. V. (2017). Criptorquidismo em cavalos-Revisão. Revista Acadêmica de Ciência Equina, 1(1), 29-40.

Schumacher, J., Schumacher, J., \& Spano, J. S. (2013). Diseases of the equine urinary tract. In T. S. Mair, S. Love, J. Schumacher, R. K. W. Smith, \& G. S. Frazer (Eds.), Equine medicine, surgery and reproduction (pp. 159-179). Elsevier Saunders. https://doi.org/10.1016/B978-0-7020-2801-4.00008-0.

Shira, M. J., \& Genetzky, R. M. (1982). Equine chryptorchidism. Iowa State University Veterinarian, 44(2), 77-81.

Silva-Meirelles, J. R., Castro, M. L., Dornbush, L. P. T. C., Guedes, R. L., Barros-Filho, I. R., \& Dornbusch, P. T. (2017). Orquiectomia em cavalos: comparação entre três técnicas em relação ao tempo cirúrgico, complicações pós-operatórias e tempo para alta hospitalar. Archives of Veterinary Science, 22(4), 73-80. https://doi.org/10.5380/avs.v22i4.48240.

Smith, J. A. (1975). The development and descent of the testis in the horse. Veterinary Annual, 15, 156-161.

Sprayberry, K. A., \& Robinson, N. E. (2014). Robinson's current therapy in equine medicine-E-Book. Elsevier Health Sciences.

Stickle, R. L., \& Fessler, J. F. (1978). Retrospective study of 350 cases of equine cryptorchidism. Journal of the American Veterinary Medical Association, 172(3), 343-346.

Thompson, F. N. (2006). Reprodução em mamíferos do sexo feminino. In W. O. Reece \& Dukes (Eds.), Fisiologia dos Animais Domésticos (pp. 644-669). Guanabara Koogan.

Trotter, G. W., \& Aanes, W. A. (1981). A complication of cryptorchid castration in three horses. Journal of the American Veterinary Medical Association, 178(3), 246-248.

Valdez, H., Taylor, T. S., McLaughlin, S. A., \& Martin, M. T. (1979). Abdominal cryptorchidectomy in the horse, using inguinal extension of the gubernaculum testis. Journal of the American Veterinary Medical Association, 174(10), 1110-1112.

Wilson, D. G., \& Nixon, A. J. (1986). Case of equine cryptorchidism resulting from persistence of the suspensory ligament of the gonad. Equine Veterinary Journal, 18(5), 412-413. https://doi.org/10.1111/j.2042-3306.1986.tb03670.x.

Histórico do artigo:

Recebido: 4 de março de 2021

Aprovado: 24 de abril de 2021
Licenciamento: Este artigo é publicado na modalidade Acesso Aberto sob a licença Creative Commons Atribuição 4.0 (CC-BY 4.0), a qual permite uso irrestrito, distribuição, reprodução em qualquer meio, desde que o autor e a fonte sejam devidamente creditados. 